\title{
Discussion: Stability and instability of foamed concrete
}

\section{Roderick Jones}

Professor, Concrete Technology Unit, Division of Civil Engineering, University of Dundee, Dundee, UK

\section{Kezban Ozlutas}

Lecturer, Department of Civil Engineering, Girne American University, The American University, Kyrenia, North Cyprus

\section{Li Zheng}

Research Fellow, Concrete Technology Unit, Division of Civil Engineering, University of Dundee, Dundee, UK

\section{Daneti Saradhi Babu}

Concrete Specialist, Alliance Concrete Singapore Pte Ltd, Singapore

\section{Contribution by D. S. Babu}

The authors have done commendable work on the stability and instability of foamed concrete (Jones et al., 2016). Instability of air voids (bubbles) is anticipated in ultra-low-density foamed concrete, which typically requires air contents in the range of $75-90 \%$ volume, and this is due to a significantly reduced spacing factor.

The increase of air void size and the coalescence of those voids, for a given quality of preformed foam, is one of the commonly faced problems in low-density $\left(<900 \mathrm{~kg} / \mathrm{m}^{3}\right)$ foamed concretes at air contents $>40-50 \%$ in general, and fwith air contents of more than $58 \%$ in particular. Comprehensive experimental and numerical study on the effects of water-to-cement (w/c) ratio on the air void system (air content, air void size, air void frequency and spacing factor), air void coalescing behaviour and increase of air void size with increase of air content/decrease of concrete density based on foamed concretes produced with CEM IIIA/S cement type has been reported previously. It is worthwhile citing Wee et al. (2006) and Wee et al. (2011) so that readers are better informed.

The increase of air void size and its coalescence increases with longer setting time of the base mix. Therefore, use of an accelerator to reduce the setting times is another alternative to increase the stability of the fine, thin walls of air voids in foamed concrete. The use of calcium sulfoaluminate (CSA) cement replacement up to $5-10 \%$ by mass is a good approach, but the substantial decrease of the base mix setting time at $10 \%$ of CSA replacement is likely to make the production of the foamed concrete difficult owing to its two-stage production process, whereby the first stage involves the production of the base mix (cement paste or cement mortar mix) and the second stage involves preformed foam additions and further mixing until the concrete is homogeneous, before placement and finishing at the actual application/designated location.

The use of CSA set controllers to address the CSA's fast setting behaviour may affect the air void stability in terms of instability due to prolonged setting behaviour. Furthermore, setting time must be finely balanced to obtain the required stability when CSA is used along with set controllers. This study did not recommend any CSA set controllers' dosage for the production of stable ultra-low-density foamed concrete. Investigation of the possibilities of micro-fine cementitious materials and/or nano particles with consideration of optimum amounts of set accelerator/CSA cement is recommended for the authors' future studies.

\section{Authors' reply}

The authors thank the discussion contributor for his comments and for drawing attention to the papers that he cites. The focus of the authors' paper was somewhat different. The aim was to confirm the hypothesis that rapid setting was an effective way of preventing instability and collapse in ultra-light foamed concrete mixes. The required fresh to solid 'transition' time for stability is, as reported, quite short, and this is challenging in practical situations. The authors did, in fact, spend a significant amount of time testing a wide range of potential ways of doing this. These included, as indeed recommended by the discussion contributor, conventional set accelerators for Portland cement, viscosity modifiers, micro-fine and rapid-hardening Portland cements, microsilica, ultra-fine fly ash, foam 'stabilising' chemical admixtures and so on. Although the authors did not report on these due to space constraints, they can confirm here that they did not work, as none resulted in either rapid enough set times or mix stability.

The authors agree that the use of CSA in the 'base' mix, although successful in terms of consistently achieving stable ultra-low-density mixes is, on the face of it, impractical; however, there is potential in this approach. CSA can be retarded and it is feasible to 'restart' reactions within the in-line foam/pump plant on-site. There are clearly hurdles and risks to this compared to using a Portland cement base mix to yield a 'standard' $600 \mathrm{~kg} / \mathrm{m}^{3}$ concrete. However, for those applications where lower densities are required, the paper points to how this could be achieved. One other point for readers is that CSA is a 'catch-all' term. The chemistry 
of this family of cements can be quite different between sources and manufacturing methods, and users need to ensure compatibility with all the constituent components of the mix to adopt this approach successfully.

The authors agree with the discussion contributor that further optimisation is possible, and hope that the understanding of the underlying mechanisms will enable researchers and users worldwide to develop ultra-low-density foamed concrete technology further.

\section{REFERENCES}

Jones MR, Ozlutas K and Zheng L (2016) Stability and instability of foamed concrete. Magazine of Concrete Research 68(11): 542-549, http://dx.doi.org/10.1680/macr.15.00097.

Wee TH, Daneti SB, Tamilselvan T and Lim HS (2006) Air-void system of foamed concrete and its effect on mechanical properties. ACI Materials Journal 103(1): 45-52.

Wee TH, Tamilselvan T and Daneti SB (2011) Effect of w/c ratio on air-void system of foamed concrete and their influence on mechanical properties. Magazine of Concrete Research 63(8): 583-595, http://dx.doi.org/10.1680/macr.2011.63.8.583. 